\title{
STUDENTS’ READINESS FOR MASSIVE OPEN ONLINE COURSES (MOOCS) IN LATVIA
}

\author{
Rita Birzina \\ University of Latvia, Latvia \\ Dagnija Cedere \\ University of Latvia, Latvia
}

\begin{abstract}
MOOCs have gained popularity increasingly more and more with their open online approach and mass engagement. They could play an important role in higher education. But the question remains whether students are ready for it. The aim of the study was to find out what students' understanding of online learning was and to what extent they were prepared for MOOCs. A research question was raised: there is a relationship among technical competencies, socio-communication competencies, self-efficacy, self-directedness and MOOCs readiness. The survey-monkey's electronic platform was used for data extraction. Open-ended questions were asked on the 4-point Likert scale. According to the research question raised, items were grouped in 5 blocks. Two hundred and forty-seven (247) students participated in the study from different Latvian universities. The descriptive statistics (Mean, Standard Deviation), Mann-Whitney $U$ tests were used in data processing in order to compare the opinions of fulltime and part-time students, Kruskal Wallis test for finding out the differences among the opinions of students who are of different age about the engagement in MOOCs. The factor analysis was used for determination main dimensions of the MOOCs readiness - sociocommunication competencies, self-efficacy, self-directness, and technical competencies. Spearman's correlation was used for identifying the correlations among these factors. The results obtained showed that there was a relationship among student's self-directness and socio-communication competencies, and self-efficacy, and readiness for MOOCs, although most students prefer face to face learning.
\end{abstract}

Keywords: MOOCs readiness, self-directedness, socio-communication competencies, technical competencies.

\section{Introduction}

Massive Open Online Courses, short MOOCs, are well known for many years and is an important part of the research area of Technology Enhanced Learning (Ebner, Schön, \& Braun, 2020, p. 75). MOOCs is a significant phenomenon that transforms the higher education (Sanagustín, Maldonado, \& Morales, 2016), a recent development in distance education improving the learning experience (Katsarova, 2015), a myth, paradox and the "fashion word" of 2012 in education (Daniel, 2012), a "big thing" in open education and distance 
Birzina \& Cedere, 2020. Students’ Readiness for Massive Open Online Courses (MOOCs) in Latvia

education (Kim, 2014; Schuwer et al., 2015; Kaplan \& Haenlein, 2016), revolution in education (Bates, 2018). Since 2008 it has been a major issue in higher education worldwide (Kim, 2016). The USA identified 2012 (Salmi, 2016) and Europe - 2013 (Goglio, 2019) "The year of the MOOCs", providing massive and open learning opportunities for all, promoting engagement in the knowledge society (Brown, 2018). MOOCs as open and online education is seen as an innovation driver for improving education with the aim of increasing the access and engagement in education by removing barriers and offering multiple ways of learning and sharing knowledge (Patru \& Balaji, 2016).

European countries are late adopters of MOOCs compared to the USA, where since 2012 MOOCs has had an impressive growth, accompanied by an enthusiastic media coverage (Goglio, 2019). In Europe and also Latvia, MOOCs are considered as (usually shorter) online courses offered by higher education institutions and which do not result in a degree qualification. Finally, higher education institutions in more than half of the countries (28) also provide courses as MOOCs (European Commission / EACEA /Eurydice (2018).

However, despite the promising opportunities for the introduction of MOOCs in higher education, its implementation is very slow. The huge number of drop-outs, students' lack of motivation to finish these courses because they do not provide official credit points and, probably, also students themselves not being ready for the self-guided study process serve as evidence for this (Fisher, 2014).

The aim of the study was to find out what students' understanding of online learning was and to what extent they were prepared for MOOCs. The research question: there is a relationship among technical competencies, sociocommunication competencies, and self-directedness and MOOCs readiness - was raised.

\section{MOOCs implementation in higher education}

MOOCs - definition. The development of terminology is dynamic and therefore changes over time show the historical continuity (Al Lily et al., 2017). Mariana Patru and Venkataraman Balaji (2016, p. 17) suggest using the adapted definition recommended by Fred Mulder and Darco Jansen (2015) "MOOCs are online courses designed for large numbers of participants, can be accessed by anyone anywhere as long as they have an Internet connection, are open to everyone without entry qualifications and offer a full/complete course experience online for free". This definition includes the essence of the abbreviation MOOCs, underlining that "Massive" means designed for an unlimited number of participants, "Open" - there is a free access for anyone and without entry qualifications, "Online" - the access from the internet using the laptop or desktop computer, a tablet computer or a smartphone); "Course" - designed reflecting a 
study course (with concrete learning goals, developed course materials, workedout assessment tools such as quizzes, feedback, an examination and a certificate of completion) and which should be implemented in a definite period of time.

Types of MOOCs. Mainly there are two types of MOOCs: xMOOCs and cMOOCs.

xMOOCs is a term coined by Stephen Downes (2012) for courses developed by Coursera, Udacity and edX. xMOOCs were the most common MOOC in 2015. The characteristic feature of them is the use of specially designed platform software, video lectures, a computerized assessment, pair assessment, supporting materials, comment/discussion space, and the presence/absence of the discussion moderation, badges or certificates, and learning analytics. It means that xMOOC tend to transmit information to a wide audience, to use short video lectures and to make assessment (Open Education Handbook, 2014; Kim, 2014).

cMOOCs are based on network learning, where learning develops through the connections and discussions between participants over social media. They have a more different education philosophy than xMOOCs, and they are more focussed on the course participants' cooperation (Bates, 2018). Actually they are more based on the learner interaction by use of connectivist and constructivist pedagogies (Open Education Handbook, 2014; Kim, 2014).

Pedagogical aspects of MOOCs. It is considered (Five ways MOOCs are influencing teaching and learning, 2016) that there are five ways how MOOCs could affect teaching and learning: (1) separating design, development, delivery and support for learning, (2) changing the nature of credit granting and credentials, (3) developing blended learning, (4) supporting the development of learning portfolios, (5) demonstrating the power of learning communities and peer tutoring.

In order to find out to what extent students of higher education institutions of Latvia are prepared for using MOOCs, it was important to explore what has been understood by the term "readiness for learning" as a holistic way of looking at the learners' preparedness to learn, emphasizing both the characteristic features of the learner himself and his social adaptation to the electronic teaching/learning environment and his technological skills. As Widodo Winarso (2016) considers readiness to learn is a situation of students who are ready or willing to do activities with full consciousness to obtain results in the form of changes in knowledge, understanding, skills, habits, values, and attitudes by observing, imitating, exercise, investigate, and the entry of new experiences on students (p. 81). In order to cooperate successfully in MOOCs courses, the following skills should be taken into account: study, self-direction, self-efficacy, motivation, communication, computer, Internet skills and access to ICT facilities. As the study of the authors about the experience of the students and academic staff of Latvia and Thailand shows (Birzina \& Na-Songkhla, 2019) the participant's engagement is an 
important factor. Studying the learners' activities in the concrete MOOC, it was found out that active participation in the course has three interconnected dimensions that ensure engagement cognitively, emotionally and socially. It is an opportunity for learners to develop of independent and self-determined learning for lifelong learning, to develop information and digital literacy, as well to improve foreign language skills (Birzina, 2015). Student Online Learning Readiness (SOLR) Model, which was used in designing the questionnaire, is well suited to evaluate students' preparedness. The model consists of four components that describe students' readiness for online learning, i.e., social competencies with the instructor, communication competencies, social competencies with classmates, and technical competencies (Yu \& Richardson, 2015).

\section{Methodology of the research}

In order to clarify students' readiness for MOOCs, a questionnaire was designed. The conceptual framework of this study was adapted from the SOLR Model proposed by Taeho Yu and Jennifer C. Richardson (2015), Cecilia Mercado (2008) and the questionnaire developed by Open University Malaysia (Subramaniam, Suhaimi, Latif, Kassim, \& Fadzil, 2019). Survey-monkey's electronic platform was used for data extraction. Open-ended questions were asked on the 4-point Likert scale (1 - strongly disagree, 4 - strongly agree). Items of the conceptual part were grouped in 5 blocks - four independent variables (socio-communication competencies, technical competencies, self-directness, and self-efficacy) and one dependent variable- MOOCs readiness (Figure 1).

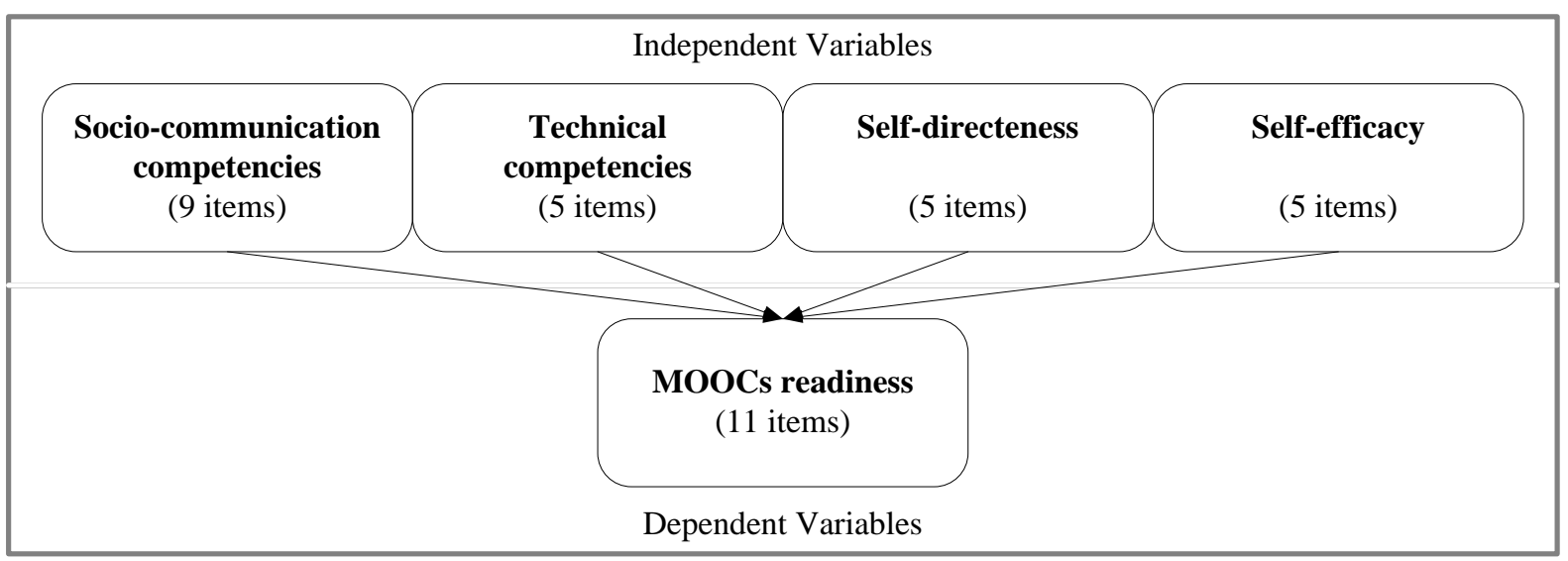

Figure 1 The conceptual framework (Adapted from T. Yu \& J.C. Richardson, 2015; C.A. Mercado, 2008; T.T. Subramaniam et al., 2019)

Principal component analysis (PCA) with a varimax rotation was used. In order to find out whether PCA is suitable for these data sets the Kaiser-Meyer- 
Olkin (KMO) measure of sampling adequacy tests and Bartlett's tests for sphericity were used. In order to establish a definite number of correct factors, the parallel analysis was applied. Spearman's correlation was used to clarify the correlations between these factors.

To compare the opinions held by full-time and part-time students, the MannWhitney U tests were used in data processing, the Kruskal Wallis test was used for sorting out differences in students' of different age groups opinions about the participation in MOOCs.

The study was carried out from January 25 to February 27, 2017; the participants were 391 students from higher education institutions of Latvia, of whom the questionnaire was fully filled in by 247 students. Of them, 196 were female (79\%) and 51 male (21\%) aged from 18 to 55 years. Most students belonged to the age group 18-25 years $(n=167$; 68\%), which means that the majority (53\%) were the students of bachelor level study programmes. Twohundred fifteen (87\%) respondents study full time. Actually all 246 students (99.6\%) have access to the internet, 234 (96.4\%) have a smart phone as well as 97.6\% have a PC / Laptop / Tablet. Approximately only 9\% $(n=22)$ of these students have enrolled in MOOCs and $23 \%(n=57)$ plan their participation.

\section{Findings of the research}

In order to explore students' opinion about their preparedness for MOOCs, first, their motivation to enrol in these courses was found out. As seen in Table 1, students are most motivated for enrolling in MOOCs by the possibility to widen their knowledge (69\%), socialising (39\%), personal interest (84\%) and networking (65\%), less (10\%) by professional development.

Table 1 Students' motivation to engage in MOOCs

\begin{tabular}{|lcc|}
\hline Enrol in a MOOC Course: & $\boldsymbol{n}$ & $\mathbf{\%}$ \\
\hline To widen knowledge & 171 & 69.2 \\
Socialising & 95 & 38.5 \\
Personal interest & 84 & 34.0 \\
Networking & 65 & 26.3 \\
Credit for university course & 33 & 13.4 \\
Continuous professional & 24 & 9.7 \\
development & 13 & 5.3 \\
Exposure to online learning & 11 & 4.5 \\
Compulsory university course & 10 & 4.0 \\
Added value to resume & & \\
\hline
\end{tabular}

The use of the Mann-Whitney U tests allowed clarifying whether there were differences in separate items about the MOOCs readiness in the opinions 
Birzina \& Cedere, 2020. Students' Readiness for Massive Open Online Courses (MOOCs) in Latvia

expressed by the full-time (FT) and part-time (PT) students. Table 2 demonstrates that there are statistically significant differences in the items about communication, the student's self-efficacy, self-directed learning and engagement. PT students in these items have higher $p$ values, which could be explained by their experience and the choice of the study form where MOOCs have a greater importance.

Table 2 Full-time and part-time students' different views on enrolment in MOOCs

\begin{tabular}{|c|c|c|c|c|c|}
\hline \multirow{2}{*}{ Item } & \multicolumn{2}{|c|}{ PL } & \multicolumn{2}{|c|}{ NL } & \multirow{2}{*}{$p$} \\
\hline & $M$ & SD & $M$ & $S D$ & \\
\hline $\begin{array}{l}\text { I am keen on meeting many new peers in my online } \\
\text { course }\end{array}$ & 2.61 & .74 & 3.00 & .63 & .015 \\
\hline I find learning online is highly engaging and interesting & 2.67 & .69 & 3.00 & .63 & .030 \\
\hline I am confident that I can perform well in an online course & 2.69 & .68 & 3.12 & .52 & .002 \\
\hline I manage my studies in accordance to my study plan & 2.93 & .67 & 3.23 & .65 & .035 \\
\hline I look forward to engage in MOOCs & 2.51 & .75 & 2.88 & .77 & .018 \\
\hline I can commit the time needed to complete a MOOC & 2.53 & .85 & 2.88 & .86 & .042 \\
\hline Searching for MOOCs & 2.06 & .70 & 2.38 & .80 & .041 \\
\hline
\end{tabular}

The Kruskal Wallis Test was used to find out the differences in students' opinions depending on their age. As shown in Table 3, there are statistically significant differences in the item "I am ready to enrol in massive open online courses" among students of different age. Students aged 26-45 years who have a greater life experience and thus are able to assess better the MOOCs possibilities choose more to enrol in such courses, while younger (18-25 years) and older students appreciate less such a possibility. As the number of students in different age groups is very different, it could serve as a limiting factor for the data interpretation.

Table 3 Response distribution depending on the respondents' age $(N=247)$

\begin{tabular}{|c|c|c|c|c|c|c|c|c|c|c|}
\hline \multicolumn{2}{|c|}{$\begin{array}{c}\text { 18-25 years } \\
(n=167)\end{array}$} & \multicolumn{2}{|c|}{$\begin{array}{c}\text { 26-35 years } \\
(n=49)\end{array}$} & \multicolumn{2}{|c|}{$\begin{array}{c}\text { 36-45 years } \\
(n=16)\end{array}$} & \multicolumn{2}{|c|}{$\begin{array}{c}\text { 46-55 years } \\
(n=8)\end{array}$} & \multirow{2}{*}{$\begin{array}{l}\text { Chi- } \\
\text { Square }\end{array}$} & \multirow[t]{2}{*}{$d f$} & \multirow[t]{2}{*}{$p$} \\
\hline$M$ & $S D$ & $M$ & $S D$ & $M$ & $S D$ & $M$ & $S D$ & & & \\
\hline 2.62 & .81 & 3.00 & .76 & 2.94 & .77 & 2.38 & .74 & 10.296 & 3 & .016 \\
\hline
\end{tabular}

In order to find out whether the respondents' answers make reciprocally noncorrelating sets of items corresponding to the developed blocs of items which afterwards could be used in designing indicators describing the MOOCs readiness, the factor analysis was performed.

The KMO measure of sampling adequacy was 0.90 and Bartlett's test of sphericity was significant $\left(c^{2}(247)=3711.22, p<.001\right)$, thus the data were 
meaningful and compatible to perform the factor analysis. The principal component analysis (PCA) was performed using the extraction method with the succeeding rotation of varimax with Kaiser normalization. Items with the factor loading no less than 0.50 were subjected to the analysis. The parallel analysis (PA) was used for establishing the number of principal components that had to be retained for the factor analysis. Thus, the three most important factors that explain $48 \%$ of the variance were defined (see Table 4 and Figure 2).

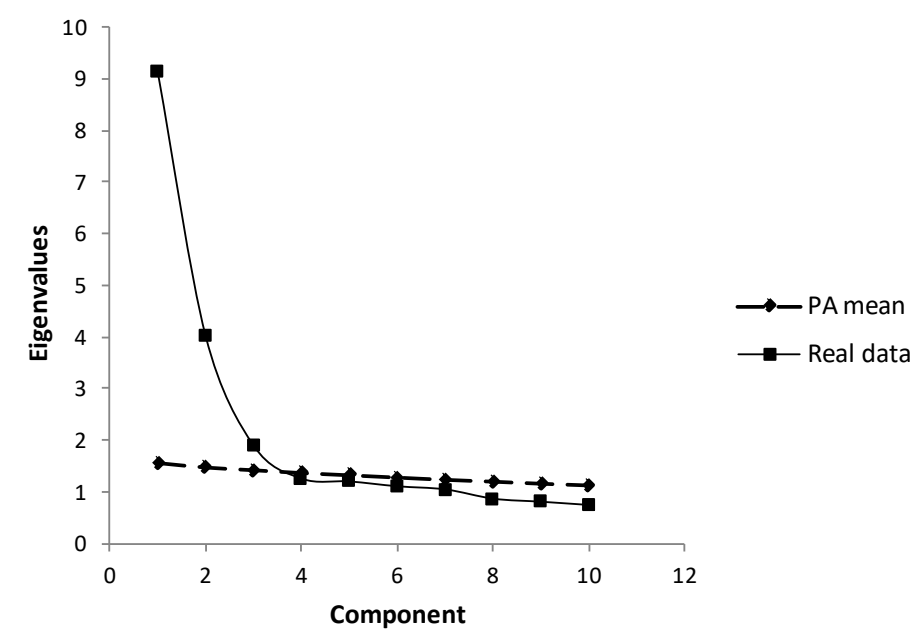

Figure 2 Plot of real data (PCA) and randomly generated eigenvalues (PA)

The pattern matrix of the factor analysis in Table 4 depicts factor loadings above 0.5 and indicates that 24 items out of 35 original items were retained (with all 8 items under MOOCs Readiness (Factor 1 (F1)) retained), and the remaining factors were reduced from four to two. The final three-factor structure in this study was of 11 items for Factor 2 (F2) re-labelled as Self-directness and SocioCommunication, 5 items for Factor 3 (F3) labelled as Self-efficacy. The factor Technological competencies was not singled out because the separate items characterizing this factor correlate similarly with the items of other factors and do not provide intrinsic interpretation in the description of the factors therefore these items were excluded from the factor analysis.

Table 4 Results of the principal component analysis with a varimax rotation of items

\begin{tabular}{|lccccc|}
\hline \multicolumn{1}{|c}{ Item } & M & SD & \multicolumn{3}{c|}{$\begin{array}{c}\text { Rotated factor } \\
\text { load values }\end{array}$} \\
\cline { 4 - 6 } & & & F 1 & F 2 & F 3 \\
\hline 29. MOOCs it is accredited by my University & 2.90 & .77 & .86 & \\
28. MOOC only if it contributes towards a degree & 2.94 & .81 & .83 & \\
25. MOOC if it is equivalent to a conventional course & 2.82 & .74 & .82 & \\
30. Ready to enrol in a MOOC & 2.72 & .81 & .81 &
\end{tabular}


Birzina \& Cedere, 2020. Students' Readiness for Massive Open Online Courses (MOOCs) in Latvia

\begin{tabular}{|c|c|c|c|c|c|}
\hline 31. Commit the time needed to complete a MOOC & 2.58 & .85 & .74 & & \\
\hline 26. Look forward to engage in MOOCs & 2.56 & .76 & .72 & & \\
\hline 27. Like to learn more about MOOCs & 2.92 & .73 & .67 & & \\
\hline 34. Open for online assessments & 2.70 & .70 & .64 & & \\
\hline 3. Able to express myself in a clear manner & 2.98 & .54 & & .67 & \\
\hline 4. Able to give constructive feedback to others & 3.13 & 69 & & .65 & \\
\hline 1. Comfortable in responding to other people's ideas & 2.95 & .69 & & .62 & \\
\hline 22. Manage studies in accordance to my study plan & 2.96 & 68 & & .62 & \\
\hline 8. Able to connect with others (peers and tutors) & 3.13 & .64 & & .62 & \\
\hline $\begin{array}{l}\text { 24. Seeking for resources and completing learning } \\
\text { tasks independently }\end{array}$ & 3.03 & 64 & & .61 & \\
\hline 21. Set up learning goals and study plan independently & 3.10 & .64 & & .60 & \\
\hline 2. Comfortable in seeking for help when necessary & 2.88 & 69 & & .59 & \\
\hline 23. Seek assistance when unable to solve problems & 3.10 & .60 & & .56 & \\
\hline 20. Have high expectations for doing well my studies & 3.06 & 69 & & .53 & \\
\hline $\begin{array}{l}\text { 7. Confident in posting questions online if does not } \\
\text { understand something }\end{array}$ & 2.75 & .75 & & .54 & \\
\hline 11. Learn well in online course & 2.45 & .79 & & & .71 \\
\hline 12. Confident for performing well in an online course & 2.75 & 68 & & & .66 \\
\hline 10. Learning online is highly engaging and interesting & 2.72 & 69 & & & .65 \\
\hline 14. Confident in using ICT system and tools & 3.08 & .66 & & & .59 \\
\hline 13. Believe anyone can learn in an online environment & 2.56 & .80 & & & .58 \\
\hline$\%$ of variance explained & & & 30 & 12 & 5 \\
\hline Eigenvalues & & & 2.77 & 3.01 & 2.54 \\
\hline Cronbach’s alpha & & & .93 & .87 & 79 \\
\hline
\end{tabular}

The description of the separated factors. F1 - MOOCs readiness describes the students' readiness to engage in such courses, mainly connecting them with such a possibility from the position of their academic studies.

F2 - Self-directness and Socio-Communication describe the student's choice to learn in a self-directed way, to determine one's own learning goals, to plan independently one's own study process and to feel independent both in choosing the study resources and the performance of tasks, at the same time not refusing consultative support. This factor also shows students' readiness to participate in the communication with course mates and the teacher, forming a constructive dialogue.

F3 - Self-efficacy demonstrates the student's confidence in oneself, that MOOCs are a challenge that could make learning more interesting and engaging. They are certain that everyone can study very well in the electronic environment.

A Spearman's correlation was run to determine the relationship between the newly designed factors. There was a medium good, positive correlation between MOOCs readiness (F1) and Self-efficacy (F3) $(r=.55, n=247, \mathrm{p}<.001)$ and a 
weak, positive correlation between MOOCs readiness (F1) and SocioCommunication and Self-directness (F2) $(r=.34, n=247, \mathrm{p}<.001)$.

\section{Conclusions}

The study clarified the students' of higher education institutions of Latvia readiness for MOOCs in the context of technical competency, students' selfdirectness, and self-efficacy. The obtained results showed that students' understanding about the MOOCs readiness differs a bit different from the division blocs of the model used in the methodology. According to Latvian students' understanding the MOOCs readiness is mainly connected with self-directedness, socio-communication competencies, and self-efficacy. Technological competencies are considered as transversal skills (the skill to work in the internet obtaining the necessary resources, the use of the e-mail and social media) and do not create problems in using the multimodal MOOCs technologies. Students with certain life experience value higher the possibilities given by MOOCs for increasing the efficiency of the study process. MOOCs are more widely accepted as courses that may be suitable for study: they must be accredited and equivalent to a conventional course, and contributes towards a degree.

Students' self-directed learning process has an essential importance for enrolling in MOOCs. Free planning of one's time and performance of concrete learning tasks attract them. The approach of the digital generation is observed in the communication aspect, admitting that in order to communicate successfully with other they need such socio-communication competencies as providing constructive feedback, constructive expression of one's own thoughts in a way that is understandable to others, and feeling comfortable in case of seeking the help. However, if they have to make a choice between face-to-face learning and online learning, they give preference to the face-to-face study process.

In general, it can be considered that MOOCs are a challenge and students are ready to accept it because they find technology-enriched learning environment attractive for themselves.

The findings of the study prove that there is a necessity for further research about pedagogical and psychological factors that affect the learning in online courses.

\section{Acknowledgements}

The authors express their gratitude to Open University Malaysia colleagues who invited University of Latvia to participate in the study about students' readiness for MOOCs. 
Birzina \& Cedere, 2020. Students’ Readiness for Massive Open Online Courses (MOOCs) in Latvia

\section{References}

Al Lily, A.E. et.al. (2017). Academic domains as political battlegrounds: A global enquiry by 99 academics in the fields of education and technology. Information Development, 33(3), 270-288.

Bates, A.T. (2018). Teaching in a digital age: Guidelines for designing teaching and learning. Vancouver: Tony Bates Associates Ltd.

Birziņa, R., \& Na-Songkhla, J. (2019). Impacts of Educational Technologies on Learning Engagement - A Case of Latvian and Thai's Learners: Learning in the Massive Open Online courses (MOOCs). International Journal of Smart Education and Urban Society (IJSEUS), 10(4), 40-54.

Birziņa, R. (2015). Massive Open Online Courses: a case study in Latvia. In B. Kim (Ed.), MOOCs and Educational Challenges around Asia and Europe (pp. 153-180). Seul: KNOU Press.

Brown, M. (2018). Why Invest in MOOCs? Strategic Institutional Drivers. In D. Jansen, L. Konings (Eds.), The 2018 OpenupEd Trend Report on MOOCs (pp. 6-9). Maastricht, NL: EADTU. Retrieved from https://tinyurl.com/2018OpenupEdtrendreport

Daniel, J. (2012). Making Sense of MOOCs: Musings in a Maze of Myth, Paradox and Possibility. Journal of Interactive Media in Education, 2012(3), p.Art. 18. DOI: http://doi.org/10.5334/2012-18

Downes, S., \& Siemens, G. (2008). 03. CCK08 - The Distributed Course. Retrieved from https://sites.google.com/site/themoocguide/3-cck08-the-distributed-course

Ebner, M., Schön, S., \& Braun, C. (2020). More Than a MOOC—Seven Learning and Teaching Scenarios to Use MOOCs in Higher Education and Beyond. In Yu S., Ally M., Tsinakos A. (Eds.), Emerging Technologies and Pedagogies in the Curriculum. Bridging Human and Machine: Future Education with Intelligence (pp. 75-87). Springer, Singapore, https://doi.org/10.1007/978-981-15-0618-5_5

European Commission/EACEA/Eurydice. (2018). The European Higher Education Area in 2018: Bologna Process Implementation Report. Luxembourg: Publications Office of the European Union.

Fischer, G. (2014). Beyond hype and underestimation: identifying research challenges for the future of MOOCs. Distance education, 35(2), 149-158.

Five ways MOOCs are influencing teaching and learning. (2016). Retrieved from https://teachonline.ca/sites/default/files/toolstrends/downloads/five_ways_moocs_are_influencing_teaching.pdf

Goglio, V. (2019). The landscape of MOOCs and Higher Education in Europe and the USA. In EMOOC2019-European MOOCs Stakeholders Summit. Vol. 2356, pp. 41-46. CEUR Workshop Proceedings (CEUR-WS. org).

Kaplan, A.M., \& Haenlein, M. (2016). Higher education and the digital revolution: About MOOCs, SPOCs, social media, and the Cookie Monster, Business Horizons, 59(4), 441-450.

Katsarova, I. (2015). Higher education in the EU: Approaches, issues and trends. European Parliamentary Research Service, European Union. Retrieved from https://www.europarl.europa.eu/EPRS/EPRS-IDA-554169-Higher-education-in-theEU-FINAL.pdf

Kim, P. (2014). Massive Open Online Courses: The MOOC Revolution. New York, NY: Routledge. 
Kim, S.W. (2016). MOOCs in higher education. Virtual learning. Retrieved from https://www.intechopen.com/books/virtual-learning/moocs-in-higher-education

Mercado, C.A. (2008). Readiness assessment tool for an eLearning environment implementation. International Journal of the Computer, the Internet and Management, 16(SP3), 18.1 - 18.11.

Mulder, F., \& Jansen. D. (2015). MOOCs for opening up education and the OpenupEd initiative. In C.J. Bonk, M.M. Lee, T.C. Reeves, \& T.H. Reynolds (Eds.), MOOCs and open education around the world. New York, NY: Routledge. Retrieved from http://www.eadtu.eu/documents/Publications/OEenM/OpenupEdMOOCs_for_opening_up_education.pdf

Open Education Handbook. (2014). Retrieved from http://ualresearchonline.arts.ac.uk/ 14102/1/openeducationhandbook2014_bis.pdf

Patru, M., \& Balaji, V. (2016). Making sense of MOOCs: A guide for policy-makers in developing countries. UNESCO: Paris.

Salmi, J. (2016). Tertiary education and the sustainable development goals-In search of a viable funding model. Retrieved from https://www.aau.org/wp-content/uploads/2016/10/Tertiary-Education-and-the-SDGs-.pdf

Sanagustín, M.P., Maldonado, J., \& Morales, N. (2016). Status report on the adoption of MOOCs in higher education in Latin America and Europe.

Schuwer, R., Jaurena, I.G., Aydin, C.H., Costello, E., Dalsgaard, C., Brown, M., Jansen, D., \& Teixeira, A. (2015). Opportunities and threats of the MOOC movement for higher education: The European perspective. The International Review of Research in Open and Distributed Learning, 16(6).

Subramaniam, T.T., Suhaimi, N.A.D., Latif, L.A., Kassim, Z.A., \& Fadzil, M. (2019). MOOCs Readiness: The Scenario in Malaysia. International Review of Research in Open and Distributed Learning, 20(3), 80-101.

Winarso, W. (2016). Assessing the readiness of student learning activity and learning outcome. Journal Pencerahan, 10, 73-87.

$\mathrm{Yu}, \mathrm{T}$., \& Richardson, J.C. (2015). An exploratory factor analysis and reliability analysis of the student online learning readiness (SOLR) instrument. Journal of Asynchronous Learning Network, 19(5), 120-141. 